\title{
PENSANDO COM E CONTRA MARILENA CHAUI
}

\author{
Nationality and democracy: Thinking with and against Marilena Chaui
}

Gustavo Hessmann Dalaqua *

\begin{abstract}
Resumo: Mediante engajamento crítico com os escritos de Marilena Chaui sobre democracia e nacionalidade, $\mathrm{o}$ artigo defende que a nacionalidade é conducente à democracia na medida em que é capaz de criar um grau mínimo de união entre os cidadãos que os permite negociar os vários conflitos que os dividem sem pôr em questão a paridade participativa e o igual pertencimento de todos a um mesmo demos. Após reconstruir a crítica de Chaui à "nacionalidade", o artigo localiza uma passagem em que a própria filósofa redefine o termo de modo a torná-lo compatível com a democracia. A nacionalidade é compatível com a democracia quando, longe de impor uma representação homogênea e estática do povo que asfixia o conflito e denega a paridade participativa, opera como um referente dinâmico que permite aos cidadãos participar igualmente da política e negociar sem violência os conflitos que os dividem, evitando assim que os diferentes grupos políticos do demos se desintegrem em diferentes demoi. Subscrevendo a definição de Chaui da democracia, o artigo recorre à articulação entre nacionalidade e democracia feita por pensadores políticos das eras moderna e contemporânea (tais quais J. S. Mill, F. Hertz e D. Miller) e sugere que é justamente porque o conflito é um produto inevitável da convivência democrática que a existência de um grau mínimo de união e igualdade entre os cidadãos é indispensável para a manutenção da democracia. Ao satisfazer semelhante exigência, a nacionalidade pode ser considerada conducente à consolidação de uma democracia ao longo do tempo.
\end{abstract}

Palavras-chave: Nacionalidade, Democracia, Marilena Chaui, Conflito, Paridade Participativa.

\begin{abstract}
By dint of a critical engagement with Marilena Chaui's writings on democracy and nationality, the article claims that nationality is conducive to democracy to the extent it upholds a minimum degree of union among citizens which allows them to negotiate the many conflicts that divide them without putting into question their participatory parity and equal belonging to the same demos. After reviewing Chaui's criticism of "nationality," the article dwells upon a passage where Chaui herself redefines nationality in a way that makes it compatible with democracy. Nationality is compatible with democracy when, far from positing a homogeneous and static representation of the people that smothers conflict and denies participatory parity, it works as a dynamic referent that permits citizens to equally participate in politics and negotiate their conflicts without appealing to violence, thus avoiding the different political groups of the demos from disintegrating into different demoi. Endorsing Chaui's definition of democracy, the article builds upon the articulation between nationality and democracy made by modern and contemporary political thinkers and surmises it is precisely because conflict is an inevitable element of democratic coexistence that the maintenance of a minimum degree of union and equality among citizens is indispensable to the stability of democracy. By satisfying such demand, nationality can be considered to be conducive to the consolidation of democracy over time.
\end{abstract}

Keywords: Democracy, Nationality, Marilena Chaui, Conflict, Participatory Parity.

\footnotetext{
* Doutorando em Filosofia pela Universidade de São Paulo, membro do Grupo de Estudos Espinosanos e bolsista Fapesp (processo nº 2015/22251-0). Email: gustavodalaqua@yahoo.com.br.
}

\begin{tabular}{|c|c|l|l|c|c|}
\hline intuitio & $\begin{array}{c}\text { ISSN } \\
1983-4012\end{array}$ & Porto Alegre & Vol.11- $\mathrm{N}^{\circ} .2$ & $\begin{array}{c}\text { Dezembro } \\
2018\end{array}$ & p.137-148 \\
\hline
\end{tabular}




\section{Introdução}

O texto que segue aborda a relação entre democracia e nacionalidade mediante uma linha de pensamento que segue com e contra Marilena Chaui: contra na medida em que, na contramão da filósofa, afirma que a nacionalidade pode ser conducente à democracia; com na medida em que se apoia em uma concepção de nacionalidade e de nação para a qual a própria autora acena em um de seus livros. ${ }^{1}$ Após reconstruir na seção seguinte (i) a crítica à nação e à nacionalidade $\mathrm{e}$ (ii) a compreensão de democracia esposada por Chaui, recorremos na seção três ao trabalho de alguns pensadores políticos que defendem e defenderam a importância da nacionalidade para a democracia (tais quais John Stuart Mill, Friedrich Hertz e David Miller) a fim de sustentar que aquela pode ser conducente a esta na medida em que gera um grau mínimo de união, respeito e solidariedade entre os cidadãos.

$\mathrm{Na}$ seção quatro afirmamos que, ao possibilitar que sujeitos provenientes de diferentes contextos sociais se enxerguem como iguais membros de um único demos, a nacionalidade impede que a explicitação dos conflitos políticos esfacele a integridade do corpo político em diferentes demoi. A democracia é, sim, como afirma Chaui, o regime do conflito e da paridade participativa. Porém, é justamente porque o conflito é um aspecto inelidível da democracia que precisamos de uma base mínima de união que nos permita negociá-lo de um modo tal que não ponha em questão o fato de que, não obstante seus conflitos, todos os cidadãos são membros de um mesmo demos e que, portanto, todos podem igualmente participar da política e denunciar em público os conflitos que enfrentam. A nacionalidade pode ser considerada conducente à democracia não só porque consegue evitar que o desenrolar dos conflitos políticos degenere para o combate como também porque, na contramão da ideologia da competência repudiada por Chaui, tende a fortalecer a percepção de que todos os cidadãos são igualmente capazes para participar da política. $^{2}$ Esses dois benefícios que a nacionalidade é capaz de gerar estão intimamente relacionados: é por reconhecer todos os nacionais como igualmente capazes para participar da política e apresentar suas queixas em público que o princípio de nacionalidade tende a evitar que os conflitos políticos que perpassam o demos degringolem para o combate físico.

\footnotetext{
${ }^{1}$ Seguindo o vocabulário de Chaui, trataremos "nação" e "nacionalidade" como termos correlatos. A "nação" designa o espaço físico, cultural, político e social de uma comunidade, a "nacionalidade", o pertencimento àquela. Dada a correlação entre os termos, à guisa de concisão, utilizaremos por vezes apenas um deles para evocar ambos.

${ }^{2}$ Tomamos de empréstimo de Chaui a distinção entre conflito (democrático) e combate (violento).
}

\begin{tabular}{|c|c|l|l|c|c|}
\hline intuitio & $\begin{array}{c}\text { ISSN } \\
1983-4012\end{array}$ & Porto Alegre & Vol.11- $\mathrm{N}^{\circ} .2$ & $\begin{array}{c}\text { Dezembro } \\
2018\end{array}$ & p.137-148 \\
\hline
\end{tabular}


Sendo assim, concluímos que a nacionalidade pode ser identificada como princípio conducente à consolidação de uma democracia ao longo do tempo.

\section{Nacionalidade e democracia na filosofia de Chaui}

À primeira vista, nada parece mais disparatado do que valer-se do pensamento político de Chaui para afirmar a importância da nacionalidade para a democracia. Afinal, a crítica aos conceitos de nação e nacionalidade marca presença em vários livros da filósofa, tais quais Ideologia e mobilização popular (1978), O que é ideologia? (1981), Conformismo e resistência: aspectos da cultura popular no Brasil (1986) e Brasil: mito fundador e sociedade autoritária (2000). ${ }^{3}$ No primeiro livro, Chaui (2014b, p. 39) explica como os integralistas postulavam uma concepção homogênea do povo que visava extirpar a divisão e os conflitos internos a fim de dar força àquilo que chamavam de "Grande Nação". Para os integralistas, a sustentação da "nacionalidade" exigia a supressão das divisões internas (CHAUI, 2014b, p. 103). De modo análogo, no livro $O$ que é ideologia? Chaui (2016, p. 53) denuncia o caráter ideológico da nacionalidade, isto é, o fato de ela "ocultar a divisão social das classes, a exploração econômica, a dominação política e a exclusão cultural, oferecendo aos membros da sociedade o sentimento da identidade social fundada em referenciais como [...] a Nação".

A crítica ao caráter ideológico da nacionalidade é retomada em Conformismo $e$ resistência: aspectos da cultura popular no Brasil. Nesta obra, Chaui (2014a, p. 89-90) assevera que

nação e povo são suportes de imagens unificadoras tanto no plano do discurso político quanto no plano das experiências e práticas sociais. [...] os dois termos têm como referência um todo uno, indiviso, se não de facto, pelo menos de jure. [...] Evidentemente, unidade e indivisibilidade não significam ausência de diversidade. Pelo contrário, o todo é visto como internamente diversificado (por exemplo, regiões no caso da nação; e grupos no caso do povo), mas a diversidade é encarada apenas como pluralidade daquilo que é, em si, uno e idêntico. Não há diferença interna.

Para Chaui (2016, p. 101), nas sociedades atuais, o discurso da nacionalidade anuvia as divisões que perpassam os diferentes grupos sociais que vivem dentro do território nacional. Via de regra, "nação" e "nacionalidade" operam como termos ideológicos que os opressores utilizam

\footnotetext{
${ }^{3}$ Com as exceções de Brasil: mito fundador e sociedade autoritária, Convite à filosofia e Simulacro e poder: uma análise da mídia, a referência aos livros da filósofa remete à paginação dos "Escritos de Marilena Chaui”, coleção organizada por André Rocha, Éricka Marie Itokazu e Homero Santiago.
}

\begin{tabular}{|c|c|c|c|c|c|}
\hline intuitio & $\begin{array}{c}\text { ISSN } \\
1983-4012\end{array}$ & Porto Alegre & Vol.11- No.2 & $\begin{array}{c}\text { Dezembro } \\
2018\end{array}$ & p.137-148 \\
\hline
\end{tabular}


para dissimular a dominação que exercem sobre os oprimidos. É perfeitamente possível, por exemplo, que um governo em crise implemente, pelo "bem da nação", fortes medidas de austeridade que precarizam a situação da classe trabalhadora sem sequer cogitar alterar as estruturas que garantem a exploração de poucos sobre muitos.

O alerta contra o caráter ideológico dos termos "nação" e "nacionalidade" é reforçado em Brasil: mito fundador e sociedade autoritária. Logo no início do livro, Chaui (2000, p. 7-8) constata que, em nossa sociedade, a nacionalidade produz

\begin{abstract}
uma representação homogênea que os brasileiros possuem do país e de si mesmos. Essa representação permite, em certos momentos, crer na unidade, na identidade e na indivisibilidade da nação e do povo brasileiros, e, em outros momentos, conceber a divisão social e a divisão política sob a forma dos amigos da nação e dos inimigos a combater, combate que engendrará a unidade, a identidade e a indivisibilidade nacionais. [...] Em suma, essa representação [homogênea do corpo político ensejada pela nacionalidade] permite que uma sociedade que tolera a existência de milhões de crianças sem infância e que, desde seu surgimento, pratica o apartheid social possa ter de si mesma a imagem positiva de sua unidade fraterna, ocultando para si mesma a violência social que a constitui.
\end{abstract}

$\mathrm{Na}$ visão de Chaui, a nacionalidade gera uma representação homogênea do povo que habita o território nacional. Ao fazê-lo, oculta o fato de que as comunidades que vivem sob jurisdição do território nacional, em verdade, são formadas por relações de dominação e hierarquias que privilegiam uns às expensas de outros. Chaui, aqui, repete a avaliação que, catorze anos antes, proclamara em Conformismo e resistência: nação e nacionalidade são termos dos quais um pensador empenhado em lutar contra a dominação deve se afastar na medida em que ambos convergem para produzir uma imagem una e indivisa do povo que escamoteia a divisão e o conflito constitutivos da ordem política.

No capítulo dois de Brasil: mito fundador e sociedade autoritária, Chaui reforça o caráter ideológico do termo "nação" - e, por conseguinte, do cognato "nacionalidade" - ao defini-lo como semióforo. De origem antiga, semióforo "é uma palavra grega composta de duas outras: semeion 'sinal' ou 'signo', e phoros, 'trazer para a frente', 'expor', 'carregar', 'brotar'” (CHAUI, 2000, p. 11). Chaui (2000, p. 12) classifica o discurso da nação e da nacionalidade de semióforico na medida em que ele seria, sobretudo, um signo que põe à frente uma representação homogênea do corpo político. Em consonância com o que escrevera anteriormente, Chaui acrescenta que a representação homogênea do povo propiciada pelos semióforos "nação" e "nacionalidade" não pode ser contestada ou ressignificada pelas pessoas comuns. Afinal, o característico do semióforo

\begin{tabular}{|c|c|c|c|c|c|}
\hline intuitio & $\begin{array}{c}\text { ISSN } \\
1983-4012\end{array}$ & Porto Alegre & Vol.11 - No.2 & $\begin{array}{c}\text { Dezembro } \\
2018\end{array}$ & p.137-148 \\
\hline
\end{tabular}


é justamente o de servir de instrumento ideológico que permite a perpetuação inconteste da dominação de poucos sobre muitos:

Embora um semióforo seja algo retirado do circuito da utilidade e esteja encarregado de [...] celebrar a unidade indivisa dos que compartilham uma crença comum ou um passado comum, ele é também posse e propriedade daqueles que detêm o poder para produzir e conservar um sistema de crenças ou um sistema de instituições que lhes permite dominar um meio social (CHAUI, 2000, p. 13).

Uma leitura justaposta dos quatro livros ora analisados nos permite, portanto, afirmar que nação e nacionalidade para Chaui são termos ideológicos que obstruem a explicitação dos conflitos e divisão sociais. Sendo assim, podemos dizer que para Chaui ambos são termos infensos ao regime democrático, uma vez que para a filósofa a democracia se define justamente como "[f]orma política na qual, ao contrário de todas as outras, o conflito é considerado legítimo e necessário [...]. A democracia não é o regime do consenso, mas do trabalho dos e sobre os conflitos" (CHAUI, 2005a, p. 24). ${ }^{4}$ Enquanto regime que considera os conflitos elementos constitutivos da existência coletiva que precisam ser explicitados e negociados, a democracia deve largar mão dos conceitos de "nação" e de "nacionalidade", haja vista o concurso de ambos soterrar o conflito.

Ademais, ambos se opõem à democracia na medida em que negam outro traço fundamental do regime democrático na compreensão de Chaui (2016, p. 196, 201): a paridade participativa. Semióforos que são, ambos reforçam a ideia de que o significado pleno da política só pode ser compreendido pelos poucos que controlam as instituições vigentes. Ambos, assim, vão ao encontro daquilo que Chaui (2016) identifica como discurso antidemocrático por excelência: a ideologia da competência. ${ }^{5}$ Tal ideologia para Chaui é contrária à democracia porque, ao passo que esta apregoa que todos os cidadãos são igualmente competentes para participar da política, aquela insiste que apenas alguns poucos detêm a competência necessária para participar da vida pública. Com efeito, a ideologia da competência vai contra um princípio fundamental da democracia: a isegoria, isto é, o direito à palavra ou o igual direito de todos de poder participar da deliberação pública e de ter suas opiniões discutidas e avaliadas (CHAUI,

\footnotetext{
${ }^{4}$ Sobre a caracterização do conflito como elemento constitutivo da democracia na obra da filósofa, ver também Chaui (1989; 2005b, p. 403-8; 2006, p. 136; 2012; 2017, p. 19; 2018, p. 103).

${ }^{5}$ Chaui (2016, p. 57) define a ideologia da competência da seguinte forma: "não é qualquer um que tem o direito de dizer alguma coisa a qualquer outro em qualquer lugar e em qualquer circunstância".
}

\begin{tabular}{|c|c|l|l|c|c|}
\hline intuitio & $\begin{array}{c}\text { ISSN } \\
1983-4012\end{array}$ & Porto Alegre & Vol.11- $\mathrm{N}^{\circ} .2$ & $\begin{array}{c}\text { Dezembro } \\
2018\end{array}$ & p.137-148 \\
\hline
\end{tabular}


2017, p. 22-3). ${ }^{6}$ Em suma, a ideologia da competência é antidemocrática porque denega os dois atributos principais da democracia segundo Chaui: ao afirmar que apenas alguns poucos têm o expertise necessário para participar da vida pública, a ideologia da competência impede que os demais cidadãos explicitem por meio da participação política os conflitos que enfrentam no dia a dia.

Apesar de ser inegável que, ao longo dos livros aqui examinados, o tom crítico com relação à "nação" e à "nacionalidade" seja de longe o preponderante, há uma passagem em que Chaui flerta com a possibilidade de concebermos ambas de um modo que não necessariamente apaga o conflito político e a paridade participativa. Em Conformismo e resistência: aspectos da cultura popular no Brasil, em um momento surpreendente do texto, Chaui (2014a, p. 97), após denunciar que o termo "nação" gera uma representação unívoca do povo e encobre o conflito, matiza o termo de um modo tal que é compatível com o reconhecimento da legitimidade do conflito político e da paridade participativa:

\begin{abstract}
A nação não é coisa nem ideia, não é um dado factual nem ideal, não é algo que possa ser circunscrito como um ser determinado nem como uma ideia a priori da razão - é uma prática política e social, um conjunto de ações e relações postas pelas falas e pelas práticas sociais, políticas e culturais para as quais ela serve de referência empírica (o território), imaginária (a comunidade cultural e a unidade política por meio do Estado) e simbólica (o campo de significações culturais constituídas pelas lutas e criações social-históricas). A nação não é; ela se faz e se desfaz.
\end{abstract}

Trata-se, como se disse acima, de um momento surpreendente do texto porque a concepção de nação que Chaui aí elabora é ignorada na continuação do livro. A ideia de que a nação possa operar como um referente empírico, imaginário e simbólico que emerge a partir das lutas e conflitos históricos dos cidadãos e que se constrói pelas falas e práticas sociais, políticas e culturais das quais todos podem igualmente participar, ou ainda, a noção de que a nacionalidade possa ser um construto dinâmico que não é posto unívoca e unilateralmente pelos de cima aos de baixo - estes insights instigantes para os quais Chaui acena desaparecem dos demais escritos da

\footnotetext{
${ }^{6} \mathrm{~A}$ ideologia da competência, em acréscimo, é infensa à democracia na medida em que propaga aquilo que alguns filósofos contemporâneos chamam de injustiça epistêmica, conceito popularizado por Miranda Fricker (2007, p. 1) que denota "algo errado que se faz a alguém especificamente no que diz respeito à sua capacidade de ser cognoscente". Como explica Chaui (2012, p. 154), a ideologia da competência inviabiliza a paridade participativa porque postula que os cidadãos não são igualmente competentes para produzir conhecimento. Porque menos competente, o grosso do povo não está em condições de participar em pé de igualdade com a elite competente, esta sim apta para construir explicações e conhecimentos sobre os temas político-sociais. Para um exame detalhado da oposição entre democracia e injustiça epistêmica, vide José Medina (2013).
}

\begin{tabular}{|c|c|l|l|c|c|}
\hline intuitio & $\begin{array}{c}\text { ISSN } \\
1983-4012\end{array}$ & Porto Alegre & Vol.11- $\mathrm{N}^{\circ} .2$ & $\begin{array}{c}\text { Dezembro } \\
2018\end{array}$ & p.137-148 \\
\hline
\end{tabular}


autora. Não só no próprio livro do qual a passagem em recuo acima se extrai, como também nos livros que o precedem e o sucedem, a tese que Chaui não cansa de afirmar é a de que "nação" e "nacionalidade" hão de ser descartadas porquanto ambas põem à frente uma representação artificial do povo que põe a perder o desenvolvimento dos conflitos políticos e a paridade participativa dos cidadãos.

\section{A defesa da importância da nacionalidade para a democracia na filosofia moderna e contemporânea}

Um dos filósofos modernos que mais defendeu a importância da nacionalidade para a democracia foi John Stuart Mill. Nas páginas finais de Considerations on Representative Government, Mill dedica um capítulo para explorar a relação entre nacionalidade e democracia. A abordagem não surpreende uma vez que tomamos em conta que o tema da nacionalidade foi investigado por muitos filósofos políticos ao longo do século XIX e, segundo Isaiah Berlin (1990, p. 247), um número considerável deles se posicionava contra a nacionalidade porque consideravam-na fonte de irracionalidade. Dentro desse contexto histórico, Mill se diferencia de seus contemporâneos, pois, ainda que critique o chauvinismo, o autor tece elogios à nacionalidade. ${ }^{7} \mathrm{O}$ próprio modo como o filósofo define o conceito no antepenúltimo capítulo de Representative Government indica que, porque favorável ao autogoverno, a nacionalidade tende a ser benéfica:

Uma porção da humanidade pode ser considerada como constituindo uma nacionalidade se ela se unir por simpatias [sympathies] comuns que não existem entre ela e outrem - o que a leva a cooperar entre si mais voluntariamente do que com outros povos, e a desejar estar sob o mesmo governo e desejar que este seja autogoverno [government by themselves] (CW XIX, p. 546).

O liame que Mill postula entre nacionalidade e autogoverno (i.e. democracia) é reforçado na página seguinte:

Onde quer que exista o sentimento de nacionalidade [...], haverá sempre uma razão prima facie para que todos os membros da nacionalidade se unam sob o mesmo governo, e um governo só para eles. Ou seja, a questão do governo deve ser decidida pelos

\footnotetext{
${ }^{7}$ Mill emprega o termo "nacionalidade" (nationality) e jamais utiliza "nacionalismo" (nationalism). No que segue, guardaremos uma distância semântica entre os termos, indicando pelo segundo o sentimento de nacionalidade que é xenófobo, chauvinista e/ou propício ao autoritarismo. Pelo primeiro, compreenderemos aquilo que Mill entendia pelo termo. Seguindo prática padrão dos comentadores do filósofo, ao citar a edição dos Collected Works of John Stuart Mill, usaremos a abreviação CW, enumerando, em seguida, o volume e a página (ex: CW III, p. 313 equivalerá a Collected Works, volume III, página 313).
}

\begin{tabular}{|c|c|l|l|c|c|}
\hline intuitio & $\begin{array}{c}\text { ISSN } \\
1983-4012\end{array}$ & Porto Alegre & Vol.11- $\mathrm{N}^{\circ} .2$ & $\begin{array}{c}\text { Dezembro } \\
2018\end{array}$ & p.137-148 \\
\hline
\end{tabular}


governados. [...] As instituições livres são quase impossíveis em um país feito de diferentes nacionalidades. Em um povo sem sentimento de solidariedade [fellowfeeling], especialmente no qual se leem e falam diversas línguas, a opinião pública unificada, necessária ao funcionamento do governo representativo, não pode existir. As influências que formam opiniões e decidem os atos políticos são diferentes nas diferentes seções do país. Conjuntos completamente distintos de líderes têm confiança nas diferentes partes do país. Os mesmos livros, jornais, panfletos e discursos não alcançam as diferentes partes do país. Uma seção [do país] não sabe que opiniões, ou que incitações, circulam nas outras partes. [...] Mesmo que todas as partes [do país] se sintam prejudicadas [pelo governo central], nenhuma sentirá que poderá contar com a fidelidade das outras para uma resistência conjunta; nenhuma terá força suficiente para resistir sozinha (CW XIX, p. 547).

Lidas em conjunto, as duas passagens nos permitem afirmar que a nacionalidade para Mill é imprescindível à democracia porque gera união, solidariedade, uma esfera pública unificada e capacidade de resistência contra governos arbitrários. Os três primeiros itens desta lista dão crédito à interpretação de John Breuilly (2011, p. 84), segunda a qual a nacionalidade para Mill “era necessária para criar o consenso público exigido por uma democracia”. Semelhante leitura encontra respaldo em outros comentadores - tais quais Georgios Varouxakis (2002, p. 4, 20 e 23), que vê no conceito de nacionalidade milliano uma base consensual indispensável para a coexistência democrática e a manutenção do igual respeito aos cidadãos provenientes dos mais diversos grupos sociais. De fato, como se lê nas citações em recuo acima, a nacionalidade para Mill é salutar porque sustém uma base de união mínima que nenhuma democracia deve arriscar perder.

Entretanto - e é aqui que nossa leitura se distancia das análises dos comentadores do filósofo -, a nacionalidade para Mill diz respeito também ao conflito. Seríamos tentados a dizer, inclusive, que a nacionalidade põe em relevo a presença do político no pensamento do filósofo, uma vez que, no limite, ela aponta para a divisão "entre amigos e inimigos" (CW XIX, p. 548). ${ }^{8}$ De acordo com Mill, o sentimento de nacionalidade discrimina "concidadãos e estrangeiros" (CW XIX, p. 547). E, não obstante o repúdio do filósofo à violência gratuita, não se deve perder de vista que, em seus últimos anos de vida, Mill passou a defender a educação militar por conta

\footnotetext{
${ }^{8}$ Valendo-nos da distinção de Chantal Mouffe - outra filósofa contemporânea que, à semelhança de Chaui, realça o caráter primacial do conflito para a democracia -, podemos dizer que a nacionalidade é o que impede que o agonismo democrático resvale para o antagonismo. De acordo com Mouffe (2000, p. 13), o característico do agonismo é que, diferente do antagonismo, "ele envolve uma relação não de inimigos, mas sim de 'adversários', adversários que se definem [...] como 'inimigos amigáveis', isto é, pessoas que são amigas porque compartilham um espaço simbólico comum, mas também inimigas porque desejam organizar esse espaço simbólico comum de modo diferente". Tanto em Mouffe quanto em Chaui, a caracterização agonística da democracia advém da leitura que ambas as filósofas fazem de Claude Lefort (1981).
}

\begin{tabular}{|c|c|l|l|c|c|}
\hline intuitio & $\begin{array}{c}\text { ISSN } \\
1983-4012\end{array}$ & Porto Alegre & Vol.11- $\mathrm{N}^{\circ} .2$ & $\begin{array}{c}\text { Dezembro } \\
2018\end{array}$ & p.137-148 \\
\hline
\end{tabular}


da solidariedade e coesão nacional que ela propiciaria às democracias representativas (CW XVII, p. 1805). A nacionalidade em Mill combina inclusão e exclusão, ou ainda, consenso e conflito. ${ }^{9}$ Ela produz um substrato consensual que permite aos cidadãos balancearam seus conflitos internos sem apelar para a força física e, além do mais, possibilita que eles deixem suas diferenças de lado e se juntem para lutar contra algum inimigo (por exemplo, um poder arbitrário interno ou externo que visa subjugá-los) caso haja necessidade.

A característica distintiva da nacionalidade é a existência de "solidariedade", a disposição dos cidadãos para "sacrificar interesses particulares em prol do nacional” (HERTZ, 1944, p. 24). O sentimento de nacionalidade tem como benefício sincronizar, ainda que de modo imperfeito, o bem de cada cidadão com o bem geral (PENNOCK, 1979, p. 246-47). A sincronização é imperfeita porque a nacionalidade não vai a ponto de criar "uma união rígida. Ela frequentemente abrange forças antagônicas” (HERTZ, 1944, p. 26). Toda sociedade democrática precisa abrigar diferença interna, e o interessante do princípio de nacionalidade para a democracia é sua capacidade de erigir um sentimento de solidariedade que une elementos sociais díspares sem apagar as rixas e conflitos existentes entre eles (CW XIX, p. 549-50). Conforme aponta o filósofo contemporâneo David Miller (1995, p. 98) em seu livro sobre nacionalidade,

Mill tinha ciência de que um sentimento comum de nacionalidade poderia coexistir com [...] diferenças culturais [...]. A tese dele permanece adequada: na medida em que ansiamos por uma forma de democracia em que todos os cidadãos estão, em alguma medida, envolvidos na discussão dos assuntos públicos, devemos atentar para as condições sobre as quais os cidadãos conseguem se respeitar e encontrar alicerces para seus acordos. Em conjuntos grandes de pessoas, apenas uma nacionalidade comum é capaz de prover o senso de solidariedade que torna isto possível. Compartilhar uma identidade nacional, é claro, não significa subscrever visões políticas similares; mas significa, sim, estar comprometido a encontrar termos sobre os quais os concidadãos nacionais concordam em viver juntos.

A nacionalidade produz identidades coletivas que são fundamentais para a política na medida em que geram poder de cooperação entre os cidadãos, que por sua vez dá vazão ao poder político (CW XIX, p. 548 e CANOVAN, 1996, p. 3). Em seu nível mais elementar, a nacionalidade tem que ver com a democracia porque, na era moderna, ela foi e continua a ser o princípio sobre o qual diferentes demoi ao redor do mundo se formam e agem coletivamente. Sem uma nacionalidade comum, a democracia é "quase impossível” porque um povo deve, em

${ }^{9}$ Sobre a articulação entre conflito e consenso na teoria democrática milliana, ver Gustavo Hessmann Dalaqua (2018).

\begin{tabular}{|c|c|l|l|c|c|}
\hline intuitio & $\begin{array}{c}\text { ISSN } \\
1983-4012\end{array}$ & Porto Alegre & Vol.11- $\mathrm{N}^{\circ} .2$ & $\begin{array}{c}\text { Dezembro } \\
2018\end{array}$ & p.137-148 \\
\hline
\end{tabular}


alguma medida, se reconhecer como constituindo um mesmo corpo soberano a fim de que aja democraticamente (CW XIX, p. 547). A democracia pressupõe a existência de um povo (demos) e, haja vista ser a nacionalidade o principal catalisador para a formação de um povo, podemos afirmar que aquela não é possível sem esta. ${ }^{10}$

\section{Apontamentos finais: em que sentido a nacionalidade é conducente à democracia?}

Para que uma democracia possa agir e perdurar no tempo, ela precisa preservar algum nível de coesão que a proteja do perigo de entropia social que a pluralidade dos seres humanos é capaz de ocasionar em uma comunidade composta por milhões de membros. Ao oferecer um referente capaz de gerar uma união mínima que evita o esfacelamento do corpo político, a nacionalidade garante que os conflitos entre os cidadãos sejam dirimidos de um modo tal que não ponha em questão o igual respeito e valor de todos, isto é, ela incute em cada um dos nacionais o respeito pela igualdade de seus concidadãos (cf. HERTZ, 1944, p. 21). Justamente porque o conflito é um produto inevitável da convivência democrática, a existência de um grau mínimo de respeito democrático, que abarque igualmente todos os cidadãos, é indispensável. ${ }^{11}$

Ao fomentar o respeito democrático, a nacionalidade minora aquilo que Chaui (2016) chama de ideologia da competência, que para a filósofa vai contra a democracia na medida em que denega a paridade participativa dos cidadãos na política. Quer dizer, a nacionalidade favorece a democracia não só porque tende a evitar que o desenrolar dos conflitos políticos degringole para o combate físico como também porque, na contramão da ideologia da competência, tende a fortalecer a noção de que todos os cidadãos são igualmente capazes para participar da política. Ambos os benefícios que a nacionalidade é capaz de gerar se relacionam de maneira íntima: é por reconhecer todos os nacionais como igualmente capazes para participar da política e apresentar suas queixas em público que a nacionalidade tende a evitar que os conflitos políticos que perpassam o demos degringolem para o combate físico. Nesse sentido, uma democracia que abolisse a nacionalidade estaria agindo de modo suicida, pois minaria um dos princípios por meio dos quais os conflitos políticos conseguem se manifestar, sucessivamente, sem derramamento de sangue ou guerra civil.

\footnotetext{
${ }^{10}$ Não surpreende, pois, que a defesa da soberania popular na era moderna tenha caminhado pari passu com a emergência da nacionalidade (GREENFELD, 1992, p. 6; HELBLING, 2009, p. 3; MILLER, 1995, p. 29-30).

11 Sobre o caráter fundamental do respeito democrático para a resolução dos conflitos em uma democracia, ver Christian F. Rostbøll (2017). Nossa compreensão do termo segue a de Rostbøll.
}

\begin{tabular}{|c|c|c|c|c|c|}
\hline intuitio & $\begin{array}{c}\text { ISSN } \\
1983-4012\end{array}$ & Porto Alegre & Vol.11- No.2 & $\begin{array}{c}\text { Dezembro } \\
2018\end{array}$ & p.137-148 \\
\hline
\end{tabular}


Poder-se-ia redarguir: mas quem disse que a manutenção de um grau mínimo de união entre os cidadãos que fortaleça o reconhecimento da paridade participativa de todos precisaria vir da nacionalidade? Não haveria outro catalisador capaz de gerar semelhante união que, à diferença da nacionalidade, não tivesse um exterior constitutivo (no caso, os estrangeiros) e incluísse todos os seres humanos do mundo? Ainda que seja possível especular sobre a viabilidade de uma democracia de alcance global que não excluísse ninguém, na prática, nenhuma democracia até hoje conseguiu se firmar sem apelar para uma concepção de nacionalidade que discrimine os nacionais (membros que integram um espaço simbólico comum que os torna iguais perante a lei nacional) dos não-nacionais (cf. CANOVAN, 1996, p. 3).

Ao afirmar a importância da nacionalidade para a democracia, nota bene, não negamos que ela possa, como Chaui bem o mostra, gerar um nacionalismo de cunho autoritário. Nossa defesa da nacionalidade em hipótese alguma deve ser lida como uma apologia do nacionalismo. Em vez disso, o que se pretendeu oferecer aqui foi uma defesa contingente do caráter democrático da nacionalidade. Posto de outra maneira, nossa intenção não foi a de insinuar que a nacionalidade é sempre conducente à democracia. Como o estudo de Chaui sobre o integralismo e a recente eleição presidencial de Bolsonaro evidenciam, nos momentos em que serve de arrimo para o nacionalismo de matiz autoritário, a nacionalidade não favorece a democracia. Seja como for, conquanto capaz de desvirtuar para um nacionalismo antidemocrático, o princípio da nacionalidade pode ser considerado conducente à democracia na medida em que consegue propiciar um grau mínimo de união que promove a paridade participativa dos cidadãos e que possibilita que a negociação dos conflitos políticos entre eles não degringole para o combate físico, garantindo, assim, a permanência do demos ao longo do tempo.

\section{Referências}

BERLIN, I. "The bent twig: On the rise of nationalism". In: The Crooked Timber of Humanity: Chapters in the History of Ideas. Nova York: Vintage Books, 1990.

BREUILLY, J. "On the principle of nationality". In: STEDMAN JONES, G.; CLAEYS, G. (eds.) The Cambridge History of Nineteenth-century Political Thought. Cambridge: Cambridge University Press, 2011.

CANOVAN, M. Nationhood and Political Theory. Cheltenham: Edwards Elgar Publishing, 1996.

CHAUI, M. "Cultura: cultuar ou cultivar". Teoria e Debate, n. 8, 1989.

CHAUI, M. Brasil: mito fundador e sociedade autoritária. São Paulo: Editora Fundação Perseu Abramo, 2000.

CHAUI, M. "Considerações sobre a democracia e obstáculos à sua concretização". In: TEIXEIRA, A. (ed.) Os sentidos da democracia e da participação. São Paulo: Instituto Pólis, 2005a.

CHAUI, M. Convite à filosofia. $13^{\mathrm{a}}$ edição. São Paulo: Editora Ática, $2005 \mathrm{~b}$.

CHAUI, M. Simulacro e poder: uma análise da mídia. São Paulo: Editora Fundação Perseu Abramo, 2006.

\begin{tabular}{|c|c|c|c|c|c|}
\hline intuitio & $\begin{array}{c}\text { ISSN } \\
1983-4012\end{array}$ & Porto Alegre & Vol.11- $\mathrm{N}^{\mathrm{o} .2}$ & $\begin{array}{c}\text { Dezembro } \\
2018\end{array}$ & p.137-148 \\
\hline
\end{tabular}


CHAUI, M. "Democracia e sociedade autoritária". Comunicação \& Informação, v. 15, n. 2, p. 149-161, 2012.

CHAUI, M. Conformismo e resistência. Belo Horizonte: Autêntica Editora; São Paulo: Editora Fundação Perseu Abramo, 2014a. (Escritos de Marilena Chaui, 4)

CHAUI, M. Manifestações ideológicas do autoritarismo brasileiro. Belo Horizonte: Autêntica Editora; São Paulo: Editora Fundação Perseu Abramo, 2014b. (Escritos de Marilena Chaui, 2)

CHAUI, M. A ideologia da competência. Belo Horizonte: Autêntica Editora; São Paulo: Editora Fundação Perseu Abramo, 2016. (Escritos de Marilena Chaui, 3)

CHAUI, M. "Comunicação e democracia". Paulus: Revista de Comunicação da FAPCOM, v. 1, n. 2, p. 18-32, 2017. CHAUI, M. Em defesa da educação pública, gratuita e democrática. Belo Horizonte: Autêntica Editora, 2018. (Escritos de Marilena Chaui, 6)

DALAQUA, G. H. "Conflict, consensus, and liberty in J. S. Mill's representative democracy". British Journal for the History of Philosophy, v. 26, n. 1, p. 110-130, 2018.

FRICKER, M. Epistemic Injustice: Power and the Ethics of Knowing. Oxford: Oxford University Press, 2007.

GREENFELD, L. Nationalism: Five Roads to Modernity. Cambridge, Mass.: Harvard University Press, 1992.

HELBLING, M. "Nationalism and democracy: Competing or complementary logics?". Living Reviews in Democracy, n. 1, p. 1-14, 2009.

HERTZ, F. Nationality in History and Politics: A Study of the Psychology and Sociology of National Sentiment and Character. Oxford: Oxford University Press, 1944.

LEFORT, C. L'invention démocratique. Les limites de la domination totalitaire. Paris: Fayard, 1981.

MEDINA, J. The Epistemology of Resistance: Gender and Racial Oppression, Epistemic Injustice, and Resistant Imaginations. Oxford: Oxford University Press, 2013.

MILL, J. S. The Collected Works of John Stuart Mill, 33 vols. Toronto: University of Toronto Press; Londres: Routledge and Kegan Paul, 1963-1991.

MILLER, D. On Nationality. Oxford: Oxford University Press, 1995.

MOUFFE, C. The Democratic Paradox. Londres: Verso, 2000.

PENNOCK, J. R. Democratic Political Theory. Princeton: Princeton University Press, 1979.

ROSTBØLL, C. F. "Democratic respect and compromise". Critical Review of International Social and Political Philosophy, v. 20, n. 5, p. 619-635, 2017.

VAROUXAKIS, G. Mill on Nationality. Londres: Routledge, 2002.

\begin{tabular}{|c|c|c|c|c|c|}
\hline intuitio & $\begin{array}{c}\text { ISSN } \\
1983-4012\end{array}$ & Porto Alegre & Vol.11 - No.2 & $\begin{array}{c}\text { Dezembro } \\
2018\end{array}$ & p.137-148 \\
\hline
\end{tabular}

